\title{
ESTUDO COMPARATIVO DAS ATITUDES \\ AVALIATIVAS DE OSCAR WILDE NA CARTA DE PROFUNDISE SUA TRADUÇÃO PARA O PORTUGUÊS BRASILEIRO
}

\author{
COMPARATIVE STUDY OF THE APPRAISAL ATTITUDES OF \\ OSCAR WILDE IN THE LETTER DE PROFUNDIS AND ITS \\ TRANSLATION TO BRAZILIAN PORTUGUESE
}

\author{
Tamyres Fernanda Silva Maciel ${ }^{*}$ \\ Adail Sebastião Rodrigues-Júnior ${ }^{* *}$
}

\section{RESUMO}

Este artigo constitui-se de uma investigação acerca dos recursos avaliativos (MARTIN, ROSE, 2003; MARTIN; ROSE, 2007; MARTIN; WHITE, 2005; MUNDAY, 2012; RODRIGUES-JÚNIOR, 2016) utilizados por Oscar Wilde em seu manuscrito De Profundis e sua tradução para o português brasileiro. A carta, escrita num contexto expecífico da vida de Wilde, quando fora aprisionado por cometer atos considerados criminosos pela sociedade da época, apresenta diversas manifestações linguísticas de cunho avaliativo. Os objetivos do trabalho foram verificar como as escolhas lexicais que exprimem afeto, julgamento e apreciação aparecem nos textos de partida e traduzido (doravante TP e TT), contribuir com as análises tradutológicas por meio de uma abordagem de base sistêmico-funcional acerca das atitudes avaliativas presentes no TP e TT e investigar a presença do sujeito social Oscar Wilde em sua carta De Profundis. Os procedimentos metodológicos utilizados foram a comparação das ocorrências de atitude avaliativa por meio de marcações das mudanças em equivalência (CATFORD, 1965; RODRIGUES-JÚNIOR; OLIVEIRA, 2015), análises dessas mudanças e as reflexões quantitativas acerca das mudanças encontradas no corpus. Foi possível identificar três tipos de mudanças no que se refere às construções linguísticas de Avaliatividade: as que não modificam os significados semânticos presentes no TP, as que modificam esses significados e as omissões. Este estudo propiciou o desenvolvimento de uma nova categoria de mudança em equivalência no âmbito das atitudes avaliativas: é o que chamamos de Mudanças Atitudinais.

Palavras-chave: Tradução Literária; De Profundis; Avaliatividade; Mudança Avaliativa.

\footnotetext{
*Universidade Federal de Ouro Preto, Ouro Preto (MG). Brasil. tamyres_fernanda@hotmail.com ${ }^{* *}$ Universidade Federal de Ouro Preto (UFOP), Ouro Preto (MG), Brasil. adail.sebastiao@gmail.com
} 


\section{ABSTRACT}

This paper is concerned with an investigation on the appraisal resources (MARTIN e ROSE, 2003; MARTIN e ROSE, 2007; MARTIN e WHITE, 2005; MUNDAY, 2012; RODRIGUES-JÚNIOR, 2016) used by Oscar Wilde in his manuscript De Profundis, in comparison with its translation into Brazilian portuguese. The letter, written on a given context of Wilde's life, when he was arrested for having committed some acts considered crimes by the society of his time, presents many linguistic manifestation of evaluative nature. The aims of the study are: i) to verify how the lexical choices that express affect, judgement and appreciation appear on the source and target texts; ii) to contribute to the analysis of translations from a systemic functional perspective, especially texts that present evaluative attitudes; ii) to discuss the presence of the social subject Oscar Wilde in his letter De Profundis. The metodological procedures used were the comparison of the shifts of equivalence in terms of attitudinal evaluation (CATFORD, 1965; RODRIGUES-JÚNIOR; OLIVEIRA, 2015), the analysis of the shifts and the quantitative discussions concerning the shifts found in the corpus. It was possible to identify three kinds of shifts referring to the linguistic constructions of appraisal: the ones that do not modify the semantic meaning potential of the source text, the ones that modify the meaning potential and the omissions. The study has developed a new kind of equivalent shift category in the scope of appraisal attitudes, which is called Attitudinal Shifts.

Keywords: Literary Translation; De Profundis; Appraisal, Attitudinal Shifts.

\section{INTRODUÇÃO}

Este estudo se insere no campo das abordagens textuais e discursivas da Tradução (cf. MUNDAY, 2008) e tem como objetivo principal investigar o funcionamento dos recursos avaliativos (MARTIN, ROSE 2003; MARTIN, WHITE 2005; MARTIN, ROSE 2007) na obra De Profundis, de Oscar Wilde, em comparação com sua tradução para o português brasileiro. Trata-se de um estudo de base sistêmico-funcional (HALLIDAY, HASAN 1985; HALLIDAY, MATTHIESSEN 2014; RODRIGUES-JÚNIOR 2016), em que os aspectos semântico-discursivos analisados foram aqueles oriundos da metafunção interpessoal. De acordo com Halliday (1985), a metafunção interpessoal lida com a interação que se estabelece entre o falante/escritor com seu ouvinte/leitor. Diversos aspectos dessa interação podem ser analisados de acordo com as escolhas lexicais utilizadas por ambos. Com base nesses aspectos, alguns pesquisadores desenvolveram a teoria da Avaliatividade (MARTIN, ROSE 2003; MARTIN, WHITE 2005; MARTIN, ROSE 2007), cujo intuito foi lançar luz sobre o léxico que exprime avaliação e as atitudes negociadas entre participantes dentro dos textos.

No campo disciplinar das abordagens textuais e discursivas da tradução aplicadas ao texto literário, tendo como teoria-base a Linguística SistêmicoFuncional, tem sido crescente o interesse de vários pesquisadores nesse âmbito do conhecimento (COSTA, 1992; VASCONCELLOS, 1997; BUENO, 2005; 
MUNDAY, 2008; RODRIGUES-JÚNIOR, 2010, 2016; RODRIGUES-JÚNIOR; BÁRBARA, 2013; entre outros). Pautados na teoria da Avaliatividade, alguns pesquisadores (MUNDAY 2012; MOUKA, SARIDAKIS, FOTOPOULOU, 2015; RODRIGUES-JÚNIOR, BARBARA 2013; RODRIGUES-JÚNIOR 2016) utilizam essa abordagem teórica no âmbito do trabalho tradutório. O estudo de caso apresentado neste artigo segue pela mesma perspectiva: trata-se de uma investigação das atitudes avaliativas em De Profundis e a análise de como essas mesmas atitudes foram traduzidas para o português brasileiro.

Oscar Wilde foi um dos maiores escritores da Era Vitoriana. Além de fazer constantes críticas às regras morais predominantes em sua época, o autor de Dorian Gray apresentava um comportamento subversivo à sociedade daquele tempo, mantendo relações homoafetivas com vários jovens dramaturgos. Por algum tempo, Wilde teve uma relação muito intensa com o lorde Alfred Douglas (Bosie), com o qual se comunicava com significativa frequência por meio de encontros públicos e cartas (cf. ELLMANN, 1988).

Após ter sido julgado culpado, e sua reputação ter sido prejudicada pelas acusações e comprovações de seu envolvimento homoafetivo com diversos jovens dramaturgos, bem como com Bosie, Oscar Wilde foi preso e submetido a trabalhos forçados no cárcere. Enquanto esteve aprisionado, escreveu uma carta dirigida a seu amante, na qual o acusa de ser responsável por seu fracasso. O manuscrito, intitulado De Profundis, fora enviado a seu amigo Robert Ross, que o publicou no ano de 1905. A carta foi traduzida para diversas línguas, como alemão, francês, espanhol, português europeu e português brasileiro (cf. ELLMANN, 1988).

A obra De Profundis, escrita originalmente no cárcere, constitui-se de uma descrição minuciosa do relacionamento entre seu autor e Bosie. Nessa descrição, Wilde utiliza atitudes avaliativas do início ao fim do manuscrito, considerando Bosie o responsável pelo fracasso que o levou ao descrédito público. No ano de 2011, a editora brasileira L\&PM Pocket lançou uma tradução do manuscrito, Júlia Tettamanzy e Maria Angela Saldanha Vieira de Aguiar, que servirá de base para a análise proposta neste estudo.

Por meio da observação de como os recursos avaliativos funcionam na obra original De Profundis em comparação com sua tradução para o português brasileiro, é possível perceber algumas mudanças no que se refere aos significados potenciais presentes nos dois textos. Para tal investigação, o conceito de equivalência dado por Catford $(1965)^{1}$ foi fundamental neste estudo.

1. Embora Catford (1965) tenha recebido algumas críticas concernentes à sua abordagem meramente estrutural, sem se preocupar em contextualizar suas análises linguísticas, seu estudo foi o primeiro a pautar-se na linguística hallidaiana. Por esse fato, as abordagens textuais e discursivas da tradução têm no estudo de Catford um importante ponto de partida. 


\section{ATITUDES AVALIATIVAS E TRADUÇÃO}

Martin \& White (2005) caracterizam as atitudes como recursos de mapeamento dos sentimentos construídos dentro do sistema linguístico de significados. Ao utilizar os mecanismos das atitudes na fala/escrita, o falante/autor demonstra um posicionamento orientado pela escolha lexical que adota no momento da produção do texto. Nas palavras dos autores, "(...) os significados atitudinais têm a tendência de espalhar e realçar as fases do discurso à medida que o falante/escritor assume um posicionamento orientado pelo afeto, julgamento ou apreciação" ${ }^{\prime 2}$. Esse sistema envolve três regiões semânticas, sendo elas a emoção, a moral e a estética (MARTIN; WHITE, 2005, p. 42). A região semântica das emoções é chamada pelos autores de afeto, que se manifesta nas reações aos comportamentos, texto/ processo e fenômenos; a região que lida com as atitudes que exprimem conduta, característica que se admira ou critica, elogia ou condena, é chamada julgamento, que envolve a avaliação dos comportamentos; e, por fim, a região que envolve a avaliação de fenômenos semióticos e naturais, de acordo com a nossa valorização ou desvalorização de objetos, coisas, é chamada apreciação, caracterizada pela avaliação dos textos/processos e fenômenos naturais. Os autores enfatizam que: "uma forma de se pensar o julgamento e a apreciação é vê-los como sentimentos institucionalizados, que nos retiram do mundo de senso comum diário para dentro dos mundos de senso não-comum onde há o compartilhamento de valores em comunidade. ${ }^{13}$ Dessa forma, entende-se que o julgamento lida com os sentimentos em matéria de idiossincrasias, isto é, como os comportamentos são ou não devem. Concomitantemente a isso, a apreciação ocupa-se dos sentimentos manifestados sobre o valor das coisas, ou seja, em que medida são estimadas ou não. Já o afeto diz respeito às emoções no campo subjetivo do sujeito social.

Uma pesquisa fundamental na interface Avaliatividade e Tradução foi o trabalho de Munday (2012), Evaluation in Translation. O autor ressalta a ideia de que as avaliações desempenham diversos papeis na construção de espaços ideológicos nos discursos, nos quais os participantes envolvidos se posicionam no movimento dialógico. No que se refere ao ato da comunicação, Munday (2012) sugere três elementos-chave: a avaliação subjetiva, a linguagem e o campo discursivo, que no

2. Nossa tradução de: "(...) attitudinal meanings tend to spread out and colour a phase of discourse as speakers and writers take up a stance oriented to affect, judgement or appreciation." (MARTIN, WHITE, 2005, p. 43).

3. Nossa tradução de: "One way to think about judgement and appreciation is to see them as institutionalized feelings, which take us out of our everyday common sense world into the uncommon sense worlds of shared community values." (MARTIN; WHITE, 2005, p. 45). 
trabalho de produção textual se inter-relacionam da seguinte maneira: a avaliação subjetiva de quem escreve por meio da linguagem, e esta que se sustenta por um sistema de crenças e valores em um campo discursivo. Sobre essa afirmação, o autor conclui que "Isso reúne as dimensões individual (subjetiva/axiológica) e social (discurso/ ideologia) por meio da linguagem, que é tanto uma expressão da individualidade quanto um apanhado de peso ideológico de seus usos em outros contextos. ${ }^{\prime 4}$ Munday (2012) também considera que "[p]recisamos lembrar, crucialmente, que toda intervenção é avaliativa e levar em conta ambas as escolhas, conscientes ou inconscientes, feitas pelo/a tradutor/a." ${ }^{5}$ Para o autor, o trabalho tradutório exige que o/a tradutor/a identifique a avaliação pretendida pelo escritor/a e a transfira apropriadamente ao texto traduzido.

Partindo de um viés que abarca a literatura gay, a pesquisa realizada por Rodrigues-Júnior \& Barbara (2013) é um exemplo de análise pautada na investigação de como os elementos linguísticos de Avaliatividade (MARTIN, 1999; MARTIN; ROSE, 2003, 2007; MARTIN; WHITE, 2005) constroem as representações avaliativas dos personagens da literatura gay em uma tradução completa e duas adaptações para o português brasileiro. Ao debruçar-se sobre as construções linguísticas que exprimem Avaliatividade, tendo em vista a obra de Oscar Wilde The Picture of Dorian Gray, Rodrigues-Júnior \& Barbara (2013) pautamse nas representações dos personagens do romance criadas por três tradutores: João do Rio, Clarice Lispector e Cláudia Lopes. Os pesquisadores lançam mão de uma análise acerca da voz narrativa existente nos processos verbais projetantes e nas mensagens que constituem os pontos de vista narrativos e os diálogos dos personagens. A pesquisa mostrou que o ponto de vista narrativo é importante para a construção dos significados, pois é o narrador quem constitui muitas das descrições avaliativas que ilustram os personagens com características do estereótipo feminino nos textos analisados. Os pesquisadores salientam que: "Se observarmos os eventos discursivos de cada trecho analisado, veremos que suas descrições ajudam a clarear os sutis significados da avaliação pretendida por Oscar Wilde, especialmente por meio do ponto de vista narrativo" ${ }^{\prime}$. Embora este estudo não se paute no eixo

4. Nossa tradução de: "This brings together the individual (subjective/axiological) and societal (discourse/ideological) dimensions through the medium of language that is both an expression of individuality and loaded with the ideological weight of its uses in other contexts." (MUNDAY, 2012, p. 12).

5. Nossa tradução de: "(...) we crucially need to remember that all intervention is evaluative and to take account of both conscious and unconscious choices made by the translator." (MUNDAY, 2012, p. 20).

6. Nossa tradução de: "If we take the discourse events of each passage, we will see that their descriptions help clarify the subtle meanings of evaluation intended by OW, especially through the narrative point of view." (RODRIGUES-JUUNIOR; BARBARA, 2013, p. 282). 
narrativo, uma vez que a obra De Profundis é uma carta, a proposta é investigar e comparar as atitudes avaliativas de Wilde e aquelas presentes em sua tradução para o português brasileiro, bem como a proposta dos autores citados.

\section{PROCEDIMENTOS METODOLÓGICOS}

O primeiro passo das análises foi o mapeamento das atitudes avaliativas presentes no texto de partida (doravante TP) em comparação com o texto traduzido (doravante TT). A partir disso, iniciou-se a fase de análise. Com base no conceito de mudanças de Catford (1965), foi possível averiguar o comportamento das atitudes avaliativas nos dois textos e evidenciar o que chamamos aqui de Mudanças Atitudinais. A fim de fundamentar esse termo, tomemos como base a noção de correspondência formal dada por Catford (1965). Esse tipo de correspondência implica qualquer categoria de texto traduzido que ocupe o mesmo lugar na categoria que se apresenta no TP. Essas categorias são as unidades gramaticais, que podem sofrer dois tipos de mudanças: mudança de nível (de um termo gramatical para um termo lexical entre línguas); e a mudança de categoria (que pode ser estrutural, de classe, de unidade ou intra-sistema). A partir desse conceito, pode-se observar que em De Profundis algumas palavras que funcionam como afeto ou julgamento ou apreciação no TP aparecem como outra atitude no TT. Por exemplo: no TP, a expressão unjustly accused (acusado injustamente) funciona como um julgamento negativo, e no TT aparece como uma apreciação negativa na sentença acusação que lhe pareça injusta, uma vez que a palavra injusta, cuja carga semântica é minimizada pela modalização pareça, caracteriza a palavra acusação. As análises começam por demonstrar ocorrências em que as mudanças atitudinais não influenciam nos significados potenciais presentes no TP. Em seguida, são apresentadas as mudanças atitudinais que influenciam e modificam os significados pretendidos no TP e, por fim, são apontadas as omissões e suas implicações no que se refere à qualidade e quantidade de mensagens do TP que não aparecem no TT. Os excertos em que houve omissões são compostos por um recorte maior do texto, de maneira que a parte omitida ficasse mais nítida no momento da análise. Por fim, foram feitos dois quadros de atitudes elaborados a partir da quantificação das ocorrências de recursos avaliativos presentes em De Profundis em comparação com sua tradução. Com esses números, e com a organização dos quadros, que são discutidos nas considerações finais deste artigo, foi possível qualificar as mudanças presentes no TT em relação ao TP, além de localizar tais ocorrências nas subcategorias das atitudes avaliativas. 
No tópico a seguir apresenta-se quinze exemplos de mudanças atitudinais encontradas no corpus, sendo cinco mudanças que não modificam os significados potenciais presentes no original, cinco mudanças que modificam os significados potenciais e cinco exemplos de omissões encontradas na comparação entre TP e TT.

\section{ANÁLISES}

No início da carta, Wilde justifica o porquê de estar escrevendo o manuscrito a Bosie, lamentando que seu companheiro não lhe escrevera nenhuma carta até aquele momento de seu encarceramento. Vejamos como Wilde começa a descrição de alguns momentos vividos com o rapaz:

1 - I have no doubt that in this letter in which I have to write of your life and of mine, of the past and of the future, of sweet things changed to bitterness and of bitter things that may be turned into joy.

Os elementos destacados em itálico são as atitudes utilizadas por Wilde. As palavras sweet e bitter funcionam como apreciações de reação que acompanham as palavras things, e as palavras bitterness e joy são atitudes de afeto de in/felicidade, negativo e positivo respectivamente, expressas pelo autor. Na tradução, o mesmo excerto apresenta-se da seguinte forma:

1a - Não tenho nenhuma dúvida de que nesta carta, em que é preciso que eu escreva sobre a sua vida e a minha, sobre o passado e o futuro, sobre coisas boas que se transformaram em amargura e amarguras que poderiam transformar-se em alegrias (...)

Os dois elementos que aparecem como afeto no TP se mantêm funcionando como afeto de in/felicidade no TT, são as palavras amargura e alegrias. $\mathrm{O}$ primeiro elemento sublinhado exprime uma atitude de apreciação de reação, assim como no TP, embora a palavra boas não apareça sempre como a equivalente da palavra sweet (normalmente utiliza-se a palavra doce como a tradução desse termo). Observase que o terceiro termo sublinhado, amarguras, é o correspondente da atitude de apreciação de reação negativa bitter things no TP, porém, no TT aparece funcionando como afeto de in/felicidade negativo. Em termos semânticos, essa escolha tradutória não compromete o significado potencial presente no TP, mas é um exemplo de mudança atitudinal.

Outra passagem que demonstra esse tipo de mudança encontra-se no seguinte trecho do TP: 
2 - If you find in it something of which you feel that you are unjustly accused (...)

A expressão em itálico é uma atitude de julgamento de propriedade negativa, uma vez que o advérbio unjustly funciona como uma caracterização do processo material accused (... unjustly accused [acusado injustamente]). O TT apresenta-se da seguinte forma:

$2 \mathrm{a}-$ Se encontrar nela alguma acusação que lhe pareça injusta (...)

O que se observa nesse excerto é o recurso tradutório da transposição, uma vez que o adjetivo presente no TP, accused, foi substituído pelo substantivo acusação no TT. Da mesma forma, o advérbio unjustly, que funciona como julgamento de propriedade negativo no TP, foi transformado no adjetivo injusta, que no TT funciona como apreciação de composição negativa do termo acusação, demonstrando, assim, mais um exemplo de mudança atitudinal.

No trecho a seguir, Wilde coloca uma expressão indireta de julgamento negativo em relação a Bosie:

3 - The gutter and the things that live in it had began to fascinate you.

Essa passagem é composta pelo processo mental fascinate (... to fascinate you [a fascinálo]) que funciona como afeto de in/satisfação positivo, pois refere-se a um sentimento de contentamento provocado em Bosie. Vejamos como acontece no TT:

3a - O esgoto e tudo o que nele vive, já tinha começado a exercer sobre você o seu fascínio.

Observa-se aqui uma tradução literal no âmbito semântico das escolhas lexicais presentes nos dois textos, porém, o que era processo mental no TP foi substituído por um substantivo no TT, demonstrando mais uma vez o recurso tradutório da transposição. Percebe-se também que o seu fascínio funciona como uma caracterização de esgoto, revelando, portanto, uma mudança atitudinal, uma vez que a expressão é uma apreciação de composição positiva do termo esgoto.

Outro exemplo de mudança atitudinal provocada pelo recurso da transposição pode ser percebido no trecho a seguir:

4 - One that is entirely ignorant of the modes of Art in its revolution or the moods of thought in its progress (...) 
A expressão destacada, composta por um advérbio e um adjetivo funciona como um julgamento de propriedade negativo no TP (... entirely ignorant... [totalmente ignorante]). No TT, optou-se pela omissão de um termo que funcione como participante e o que era adjetivo no TP passou a ser um processo mental acompanhado do advérbio inteiramente:

4a - É possível ignorar inteiramente todas as formas que a arte pode assumir em suas diversas manifestações ou os processos de evolução do pensamento (...)

No decorrer do manuscrito, Wilde salienta, muitas vezes, seus sentimentos em ter que escrever a carta. Na passagem a seguir, o autor expressa também o que considera ser um possível sentimento de Bosie ao ler a carta:

5 - Remember also that whatever is misery to you to read ${ }_{\llcorner}$is still greater misery to me to set down.

Nesse excerto, o autor utiliza o grupo nominal misery [miséria] e greater misery [miséria maior] para caracterizar os processos to read e set down respectivamente. Por se tratar de uma distinção a respeito da reação de cada um diante da carta, o grupo nominal destacado funciona como apreciação de reação negativa. Na tradução, essa atitude aparece como afeto negativo de in/felicidade, com o processo mental sofral sofri, demonstrando o recurso tradutório da transposição (de grupo nominal para processo mental) e indicando mais um tipo de mudança atitudinal:

5a - Lembre-se também que por mais que sofra ao ler esta carta, eu sofri muito mais ao escrevê-la.

A seguir, vejamos exemplos das mudanças atitudinais que modificam os significados potenciais presentes no TP.

Ao explicar as razões que o levam a escrever a carta, Wilde coloca uma observação em que faz uso de uma apreciação de composição negativa (false). No TT, observa-se que não há nenhuma palavra que exprima avaliação, e a expressão utilizada no TP foi substituída por uma única palavra (justificativa):

6 - If you find one false excuse [lit. desculpa falsa] for yourself, you will soon find a hundred, and be just what you were before.

6a - Pois se conseguir encontrar uma só justificativa para o seu comportamento, não tardará a encontrar mais de cem e voltará a ser exatamente o que era antes. 
Essa passagem, portanto, revela uma mudança atitudinal que compromete o significado potencial presente no TP.

Ao se referir à tradução que solicitou a Bosie de sua obra intitulada Salomé, Wilde faz uso de uma circunstância em que exprime seu posicionamento em relação às discussões que os dois levavam:

7 - We had, not unnaturally indeed, differed on the question of the artistic value of your translation of Salome, so you contented yourself with sending me foolish letters on the subject.

Nessa passagem, o autor utiliza o grupo adverbial not unnaturally indeed [essa expressão enfatiza a ideia irônica de naturalmente, de fato] demonstrando que as divergências ideológicas nas discussões dele e de seu companheiro eram corriqueiras. Uma vez que essa expressão trata-se de um posicionamento crítico de Wilde, e sua colocação nesse contexto carrega um tom de ironia diante de sua relação com Bosie, a expressão funciona como uma apreciação de composição positiva. Outra expressão atitudinal nesse excerto é a apreciação de composição negativa foolish que caracteriza o grupo nominal letters. Vejamos como acontece no TT:

7a - Tínhamos discutido a propósito da qualidade artística de sua tradução da Salomé, o que era aliás bastante compreensível. Seja como for, naquela primeira semana você se limitou a me enviar cartas bastante tolas sobre o assunto.

Nesse caso, optou-se pela expressão o que era aliás bastante compreensível, que funciona como uma apreciação de reação positiva, já que se trata de uma descrição avaliativa relacionada ao ato de discussão dos dois. A palavra compreensível, de acordo com o Dicionário Houaiss de Língua Portuguesa (2007), exprime uma ideia de entendimento e se refere a algo acessível, de fácil percepção. A escolha tradutória, portanto, não carrega a mesma carga semântica presente no original. Percebe-se que a mudança atitudinal nesse excerto está na escolha do léxico que modifica o tipo de apreciação e apaga a ironia expressa por Wilde no TP. Há a inserção da expressão Seja como for, que pode ser interpretada como uma tentativa de resgate ao assunto principal, isto é, a discussão em relação à tradução, e a apreciação de composição negativa bastante tolas manteve-se equivalente à escolha lexical presente no original.

Quando começa a citar os fatos que aconteceram enquanto os dois mantinham uma relação afetivo-amorosa, Wilde expressa, por meio de uma realização indireta, seu estado de espírito quando Bosie não estava com ele: 
8 - (...) I met you either too late or too soon, I don't know which. When you were away I was all right. [lit. quando você estava fora, en ficava bem.]

A expressão destacada revela uma atitude de afeto de felicidade positiva, podendo ser entendida como "eu ficava bem" ou algo similar. No TT, a atitude de afeto é substituída por uma expressão que remete a outro tipo de característica cognitiva do autor:

$8 a-(\ldots)$ a verdade é que eu o conheci demasiado tarde - ou demasiado cedo, não sei. Quando você estava longe, eu voltava ao normal.

A mudança atitudinal percebida aqui é a utilização no TT de uma expressão de julgamento positivo indireto, e que demanda a interpretação do leitor no que se refere ao sentido pretendido com a palavra normal. Cabe a questão "qual o estado de espírito normal de Wilde?". Isso não necessariamente pode ser respondido como "ficava bem", mas como "sentia-me criativo" por exemplo, como aparece em outras passagens do texto. Essa passagem, portanto, revela uma mudança atitudinal que interfere no significado potencial expresso no TP.

No trecho a seguir, Wilde conta sobre o momento em que fora condenado à prisão. Ele descreve que, em vez de buscar esclarecimentos com seu advogado para tentar alternativas de reverter a situação, atendeu ao pedido de Bosie para que viajassem juntos. Nessa descrição, o autor menciona o termo utilizado pelo pai de Bosie se referindo à armadilha na qual Wilde se encontrava naquele momento. A armadilha se deu, segundo o autor, pelo fato de o pai de Bosie ter enviado uma carta a Wilde com os seguintes dizeres: "To Oscar Wilde, ponce and Sodomite" [Para Oscar Wilde, proxeneta e Sodomita]. Na ocasião, Wilde foi convencido por Bosie a denunciar seu pai, e acabou sendo vencido por ele perante a justiça:

9 - At a time when I should have been in London taking wise counsel, and calmly considering the bideous trap in which I had allowed myself to be caught - the boobytrap as your father calls it to the present day (...)

Nesse trecho observa-se diversas atitudes avaliativas: wise [... wise counsel ... (sábio conselho)] - apreciação de composição positiva; calmly [calmamente] - afeto de segurança positivo; bideous [... bideous trap... (cilada/armadilha espúria, revoltante)] - apreciação de reação negativa; e finalmente booby-trap [armadilha] - apreciação

7. Esse adjetivo também é usado como ofensa à forma de se vestir e de se comportar dos homossexuais da época. 
de reação negativa. O termo booby-trap, tem a seguinte definição no Dicionário Oxford de Língua Inglesa (2005): "uma bomba escondida que explode quando o objeto conectado a ela é tocado; um dispositivo escondido caracterizado como uma brincadeira para surpreender alguém, por exemplo, um objeto colocado acima da porta que cairá no primeiro que passar por $\mathrm{ali}^{\prime \prime}{ }^{8}$. No TT, grande parte dessas atitudes são mantidas em seus significados potenciais equivalentes,

9a - (...) no momento em que eu deveria estar em Londres, ouvindo os sábios conselhos de um advogado e examinando calmamente a bedionda armadilha em que me deixara prender — armadilha digna de uma criança, como seu pai a chama até hoje (...)

que são as expressões: sábios - apreciação de composição positiva; calmamente - afeto de in/segurança positivo; bedionda - apreciação de reação negativa. A última atitude presente nesse trecho apresenta uma mudança atitudinal: armadilha digna de uma criança é um julgamento de realização indireta negativo. Nesse caso, houve a inserção de uma expressão carregada de um sentido proveniente da subjetividade no trabalho tradutório, isto é, o termo expresso no TP foi interpretado pelas tradutoras como uma atitude infantil, o que demonstra mudança no significado potencial do termo no TT.

Em algumas partes do manuscrito, Wilde conta que se comunicava com a mãe de Bosie por meio de cartas. Em uma descrição dessas correspondências, o autor declara:

10 - At the end she stated that she felt bound to declare that your friendship with me, in her opinion, had so intensified your vanity that it had become the source of all your faults, and earnestly begged me not to meet you abroad.

As atitudes presentes nesse excerto são: bound - julgamento de tenacidade negativo; vanity - julgamento de propriedade negativo; faults - apreciação de composição negativa; e earnestly - julgamento de veracidade positivo. No TT, grande parte das atitudes são traduzidas literalmente e não se modificam em termos de atitudes:

10a - Ao final, afirmava sentir-se obrigada a dizer que, na sua opinião, a nossa amizade intensificara de tal forma a sua vaidade que esta acabara por se tornar a origem de

8. Nossa tradução de: "a hidden bomb that explodes when the object that is connected to is touched; a hidden device that is meant as a joke to surprise sb, for example, an object placed above a door so that it will fall on the first person who opens the door." (Oxford Dictionary, 2005, p. 165). 
todos os seus erros e me implorava, angustiada, para que eu não fosse encontrá-lo no continente.

Porém, o julgamento de tenacidade positivo presente no TP transformarase em uma atitude de afeto de in/felicidade negativo (angustiada). Essa mudança atitudinal revela um sentido muito diferente daquele presente no texto original, além de evidenciar a subjetividade das tradutoras no que se refere à interpretação do termo earnestly, que normalmente é traduzido por 'sinceramente', 'seriamente' ou 'fervorosamente'.

A seguir, há alguns dos casos em que a tomada de decisão na tradução foram as omissões.

Na passagem em que Wilde conta sobre a morte do irmão de Bosie, o autor descreve que o irmão mais velho de seu companheiro teria sido encontrado morto em um valo e, ao seu lado, havia uma arma com todas as balas detonadas. Até que descobrissem o real fato sobre a morte do irmão de Bosie, diversas suspeitas foram levantadas:

11 - The borror of the circumstances of the tragedy, now known to have been an accident, but then stained with a darker suggestion; the pathos of the sudden death (...)

Wilde se refere às suspeitas por meio dos seguintes tipos de atitude: borror afeto de in/segurança negativo; tragedy - apreciação de composição negativa; darker - apreciação de composição negativa; e pathos - apreciação de reação negativa. No TT, quase todas as atitudes foram mantidas: horror - afeto de in/segurança negativo; tragédia - apreciação de composição negativa; e patético - apreciação de reação negativa.

$11 \mathrm{a}-\mathrm{O}$ borror das circunstâncias em que ocorrera a tragédia — que agora sabemos ter sido um acidente —, [OMISSÃO] o patético de morte súbita (...)

Percebe-se que a expressão responsável por sugerir um mistério acerca da morte do irmão de Bosie é omitida, o que provoca uma mudança atitudinal significativa em relação ao sentido presente TP.

À medida que vai chegando ao final do manuscrito, Wilde cita algumas passagens da Bíblia e descreve suas interpretações sobre o livro. Para ele, a vida de Cristo é uma grande inspiração para os artistas. Nesse momento, o autor fala de uma conversa que tivera com um amigo em um café em Paris: 
12 - I remember saying once to André Gide, as we sat together in some Paris cafe, that while Metaphysics had but little real interest for me, and Morality absolutely none, there was nothing that either Plato or Christ had said that could not be transferred immediately into the sphere of Art, and there find its complete fulfillment. It was a generalization as profound as it was novel. Nor is it merely that we discern in Christ that close union of personality with perfection (...)

Pode-se perceber nesse trecho que há duas atitudes de apreciação de valor positivo: real, absolutely none, que complementa a apreciação anterior, e a expressão composta pelo adjetivo profound. No TT, a expressão de apreciação que fecha o raciocínio de Wilde foi omitida, que inibe mais um posicionamento crítico de Wilde:

12a - Lembro que uma vez disse a André Gide, quando conversávamos sentados num café qualquer de Paris, que, embora a metafísica tivesse muito pouco interesse para mim e a moral absolutamente nenbum, não havia nada que Platão ou Cristo tivessem dito que não pudesse ser transposto imediatamente para o âmbito da arte e ali encontrar completa realização. [OMISSÃO]. E não é porque podemos perceber em Cristo aquela união da personalidade com a perfeição (...)

Em uma das passagens em que cita a Bíblia, Oscar coloca a seguinte afirmação a respeito do amor:

13 - Love is a sacrament that should be taken kneeling, and Domine, non sum dignus should be on the lips and in the hearts of those who receive it. I wish you would sometimes think of that. You need it so much. If I ever write again, in the sense of producing artistic work, there are just two subjects on which and through which I desire to express myself (...)

Algumas atitudes são observadas: love - afeto de in/felicidade positivo; should be taken kneeling; should be on the lips and in the bearts - julgamentos de realização indireta positivos; wish e desire - afetos de des/inclinação positivos; e you need it so much julgamento de realização indireta positivo. No TT, observa-se que algumas atitudes se mantêm:

13a - O amor é um sacramento que deveria ser recebido de joelhos, e Domine, non sum dignus deveria estar nos lábios e nos coraçôes daqueles que o recebem. [OMISSÃO]. Se algum dia eu voltar a escrever, isto é, a criar uma obra artística, há apenas dois temas sobre os quais e através dos quais desejaria expressar-me (...) 
Todavia, o afeto desiderativo que exprime a vontade que Wilde tem em relação a Bosie e seu julgamento de que ele considera ser necessário que o rapaz saiba a respeito de o amor ser um sacramento foram omitidos no TT. Outra passagem em que as atitudes avaliativas voltadas a Bosie são poupadas encontra-se no trecho a seguir:

$14-(\ldots)$ while to propose to be a better man is a piece of unscientific cant, to have become a deeper man is the privilege of those who have suffered. And such I think I have become. You can judge for yourself. If after I go out a friend of mine gave a feast (...)

Grande parte das atitudes são julgamentos: better [melhor] e deeper [mais sério] - julgamentos de normalidade positivos; privilege - julgamento de propriedade positivo; suffered - afeto de in/felicidade negativo; I bave become - julgamento de realização indireta positivo; e por fim you can judge for yourself [você pode julgar por si mesmo] - julgamento de realização indireta negativo. Vejamos no TT:

$14 \mathrm{a}-(\ldots)$ enquanto que propor-se conscientemente a ser um novo homem é apenas uma hipocrisia anticientífica, tornar-se um bomem mais sincero é um privilégio daqueles que sofreram. E é exatamente isso que eu espero ter me tornado. [OMISSÃO]. Se depois que eu estiver livre um amigo oferecer uma festa (...)

Observa-se que os julgamentos e outras atitudes presentes no TP se mantêm. O único termo omitido é o julgamento que se refere diretamente a Bosie. A seguir, mais uma ocorrência dessa tomada de decisão:

15 - To each of us different fates have been meted out. Freedom, pleasure, amusements, a life of ease have been your lot, and you are not worthy of it. My lot has bee n o ne of public infamy, of 1 ong imprisonment, of misery, of ruin, disgrace, and I am not worthy of it either-not yet, at any rate.

No TP, as seguintes atitudes aparecem: pleasure - afeto de in/satisfação positivo; amusements - apreciação de reação positiva; life of easy - apreciação de realização indireta positiva; you are not worthy - julgamento de veracidade negativo; misery - afeto de in/felicidade negativo; ruin e disgrace - apreciações de composição negativas; I am not worthy - julgamento de veracidade negativo. Vejamos o TT:

15a - A cada um o destino reserva uma sorte diferente: [OMISSÃO] a mim coube o quinhão da desonra e do descrédito, de uma longa prisão, da desgraça, da ruína e da angústia - mas eu não os mereço, pelo menos, ainda não. 
Percebe-se que todas as apreciações e o julgamento referente a si mesmo foram mantidos, mas as atitudes avaliativas que se referem a Bosie foram omitidas.

\section{DISCUSSÃO CONSIDERAÇÕES FINAIS}

Os dois quadros de atitudes elaborados a partir das ocorrências de recursos avaliativos presentes no TP e TT de De Profundis foi essencial para a observação e quantificação desses recursos no corpus. Com esses números, e com a organização do quadro, foi possível qualificar as diferenças presentes no TT em relação ao TP, além de localizar tais ocorrências nas subcategorias das atitudes avaliativas. $\mathrm{O}$ primeiro ponto a se observar é a proporção de atitudes presentes no TP e no TT, de acordo com as quantidades nos dois quadros de atitudes. Observa-se na Figura 1 as quantidades e tipos de atitudes presentes no TP:

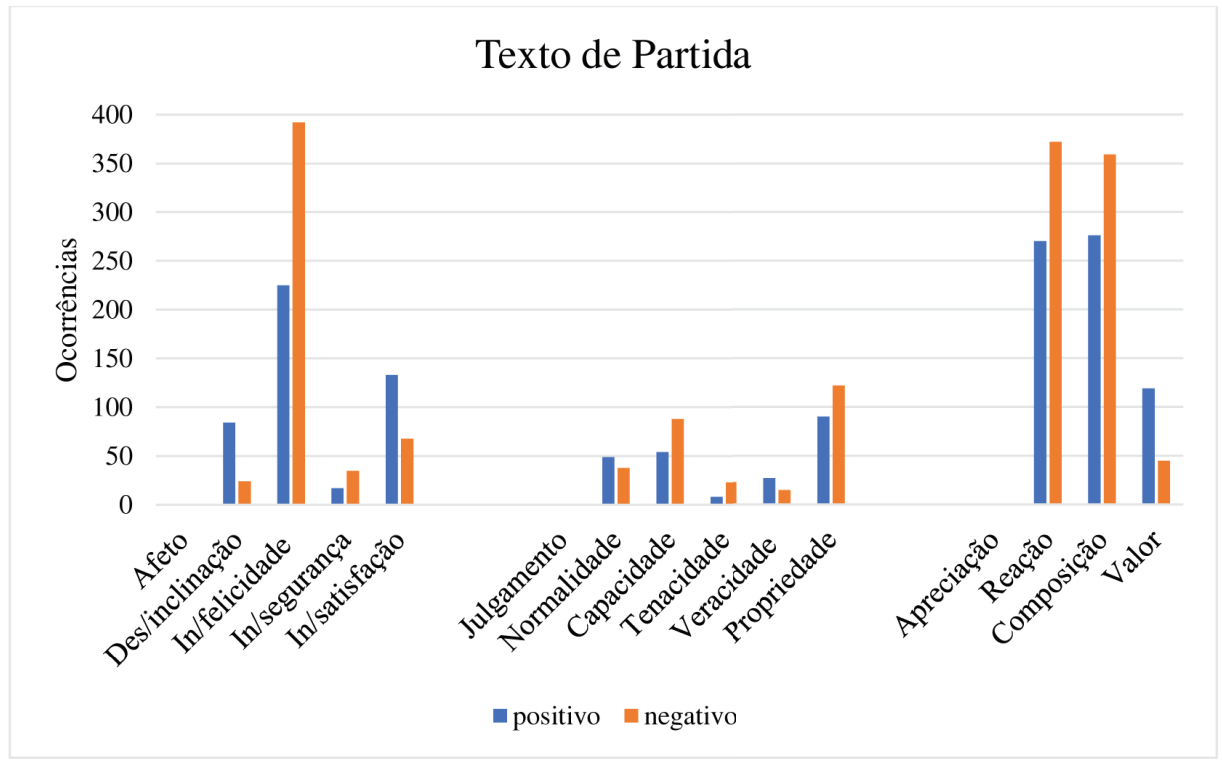

Figura 1: Gráfico ilustrativo das atitudes avaliativas presentes no TP

A Figura 2 demonstra as quantidades e tipos de atitudes avaliativas no TT: 


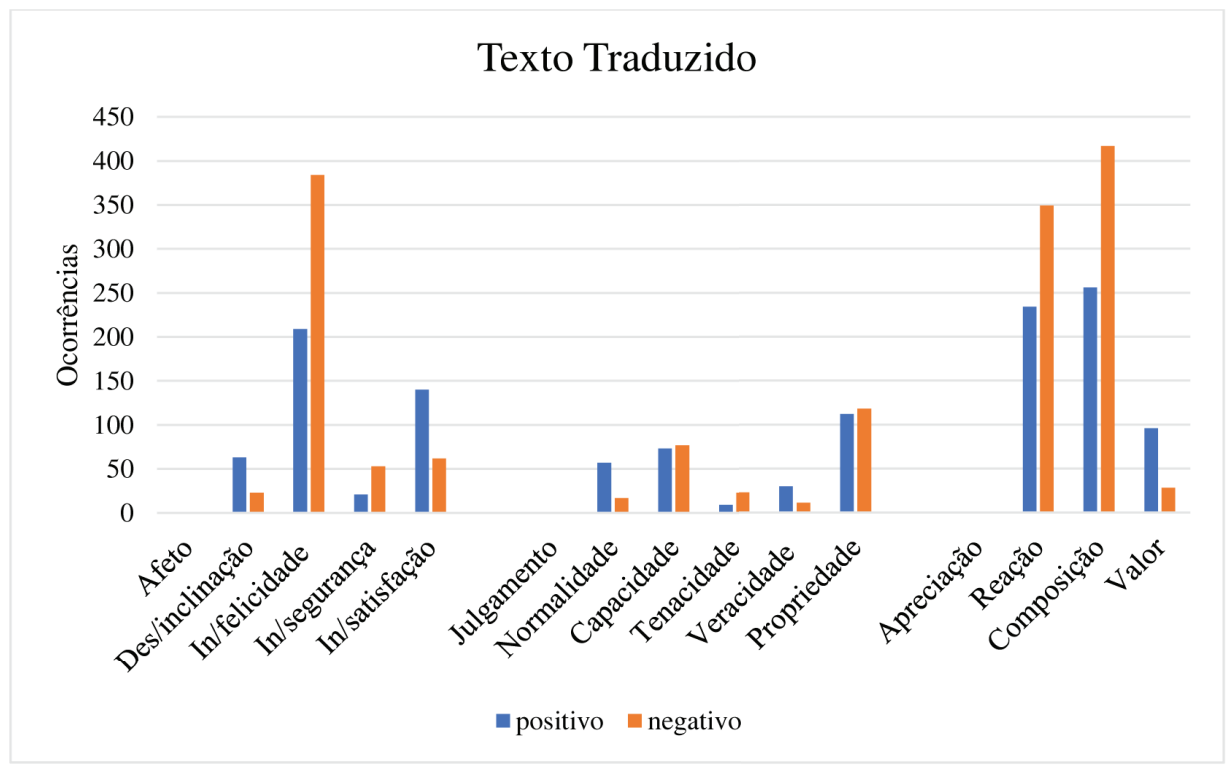

Figura 2: Gráfico ilustrativo das atitudes avaliativas no TT.

As ilustrações demonstram que as quantidades de atitudes são proporcionais na maioria das subcategorias observadas. Os recursos avaliativos mais utilizados por Wilde no TP são os afetos de in/felicidade e as apreciações, uma vez que o autor faz uso desses recursos em muitas descrições de seus sentimentos, das coisas e dos lugares que cita. Observa-se que no TT as proporções demonstram-se quase as mesmas se comparadas com os dados do TP.

Os números são quase similares, salvo as atitudes de julgamento de normalidade negativo, que no TT diminuem drasticamente em relação ao TP; os julgamentos de capacidade e de propriedade no TP são mais abundantes na perspectiva negativa, sendo que no TT essas duas quantidades se assemelham; e as apreciações de composição negativa apresentam-se mais abundantes no TT do que no TP.

A observação das diferenças no trabalho tradutório da obra De Profundis foi crucial para uma reflexão acerca das metodologias de tradução aplicadas ao texto literário. Conforme os exemplos descritos a seguir, pode-se perceber alguns recursos tradutórios e o que representam de diferentes em relação ao TP. O exemplo 1, (sweet things/coisas boas), caracteriza-se por inibir o tom metafórico expresso no TP, isto é, há no TT tomadas de decisão que expressam as mesmas mensagens do TP, porém em seus sentidos literais. Os exemplos 2 (unjustly accused/acusação que lhe pareça injusta), 
3 (fascinate you/ o seu fascínio), 4 (entirely ignorant/É possível ignorar inteiramente) e 5 (misery, great misery/sofra, sofri) apresentam o recurso tradutório da transposição. Os exemplos 6 (false excuse/ justificativa) e 7 (not unnaturally indeed/ o que era aliás bastante compreensivel) são ocorrências em que o tom depreciativo das escolhas lexicais utilizadas por Wilde é modificado. O exemplo 8 (I was all right/ eu voltava ao normal) demonstra a subjetividade no trabalho tradutório, visto que há a interpretação das tradutoras nas tomadas de decisão, o que acarreta mudanças importantes nos significados potenciais. Os exemplos 9 (booby-trap/ armadilha digna de uma criança) e 10 (earnestly begged/ implorava, angustiada) evidenciam a subjetividade no trabalho tradutório, visto que há a interpretação das tradutoras nas tomadas de decisão, o que acarreta mudanças nos significados potenciais. O exemplo 11 (but then stained with a darker suggestion) exprime, no TP, uma construção importante colocada pelo autor, o que revela um tom de mistério acerca do ocorrido com o irmão de Bosie. Essa omissão no TT é prejudicial no que se refere ao conteúdo ideológico presente no TP. O exemplo 12 (It was a generalization as profound as it was novel) representa a inibição de um posicionamento crítico de Wilde em relação à literatura. Os exemplos 13 (I wish you would sometimes think of that, You need it so much), 14 (You can judge for yourself) e 15 (Freedom, pleasure, amusements, a life of ease bave been your lot, and you are not worthy of it) são julgamentos explícitos de Wilde para Bosie, e suas omissões no TT provocam uma amenização significativa no que se refere ao posicionamento crítico do autor em relação a seu companheiro.

Este estudo constituiu-se de um apanhado de teorias no campo disciplinar das abordagens textuais e discursivas da tradução em diálogo com a LSF, mais precisamente a vertente da Avaliatividade, para a análise de como os recursos avaliativos utilizados por Oscar Wilde foram retextualizados na tradução de De Profundis. O corpus nos mostrou três tipos de mudanças atitudinais possíveis: as que não modificam os significados potenciais presentes no TP, as que modificam esses significados e as omissões. Se nos propusermos a colocar um panorama geral dessas mudanças, podemos dizer que elas provocaram uma amenização, sobretudo no âmbito dos julgamentos, no que concerne às críticas que Wilde faz diretamente ao seu companheiro. Foi possível perceber também que o aporte teórico da Avaliatividade foi eficiente na busca dos recursos linguísticos que exprimem avaliação, e a comparação desses recursos com aqueles que aparecem no texto traduzido demonstrou que a teoria avaliativa corrobora os estudos tradutológicos voltados à escrita literária.

Esse estudo também foi importante para propor reflexões sobre o fazer tradutório. As diversas teorias que abarcam a tradutologia, seus métodos e propostas de recursos serviram como referência fundamental nas análises e em suas descrições. 


\section{REFERÊNCIAS BIBLIOGRÁFICAS}

BAKER, M. (2001). In Other Words - a coursebook on translation. London and New York: Routledge,

BÁRBARA， L.; RODRIGUES-JÚNIOR， A. S. (janeiro/março 2013). Linguistic constructions of appraisal in the novel The Picture of Dorian Gray and its brasilian translation and adaptations: an exploratory analysis. Revista Brasileira de Linguística Aplicada, Belo Horizonte, v. 13, n. 1, p. 229-255.

CATFORD, J. C. (1965). A Linguistic Theory. LONDON: Oxford University Press.

ELLMANN, R. (1988). Oscar Wilde. São Paulo: Schwarcz.

GOLVEIA, C. A. M. (janeiro/junho 2009). Texto e gramática: uma introdução à linguística sistêmico funcional. Revista Matraga, Rio de Janeiro, v. 16.

HALLIDAY, M. (1998). On the grammar of Pain. In: BEDNAREK, M.; HILPERT, M.; MACKENZIE, J. L. Functions of Language. Australia: John Benjamins Publishing Company. p. 1-32.

HALLIDAY, M. A. K. M. C. (2014). Introduction of Funcional Grammar. Forth Edition. ed. London and New York: Routledge.

HALLIDAY, M. A. K. (2001). Towards a theory of good translation. In: STEINER, E.; YALLOP, C. Exploring Translation and Multilingual Text Production: Beyond Content. Berlin: Mouton de Gruyter. p. 13-18.

HALLIDAY, M. A. K.; HASAN, R. (1985). Language, context and text: Aspects of language in a socio-semiotic perspective. Victoria: Deakin University Press.

HORNBY, A. S. (2005). Oxford Advanced Learner's Dictionary: of Current English. $7^{\mathrm{a}}$. ed. New York: Oxford University Press.

HOUAISS, A. (2009). Dicionário Houaiss da Língua Portuguesa. 1. ed. Rio de Janeiro: Objetiva.

LÍSIAS, R. (2009). Introdução. In: WILDE, O. O Retrato de Dorian Gray (tradução de João do Rio). São Paulo: Hedra. p. 9-22.

MARTIN, J. R.; ROSE, D. (2003). Working with discourse. Londres: Continuum.

MARTIN, J. R.; ROSE, D. (2007). Working with discourse: meaning beyond the clause. $2^{\mathrm{a}}$. ed. New York: Continuum. 
MARTIN, J. R.; WHITE, P. R. R. (2005). The language of evaluation: appraisal in English. New York: Palgrave Macmillan.

MOUKA, E.; SARIDAKIS, I.; FOTOPOULOU, A. (2015). Racism goes to the movies: A corpus-driven study of cross-linguistic racist discourse annotation and translation analysis.

MUNDAY, J. (2001). Introducing to Translation Studies: Theories and Applications. Londres e Nova York: Routledge.

MUNDAY, J. (2008). Introducing Translation Studies. $2^{\mathrm{a}}$. ed. London and New York: Routledge.

MUNDAY, J. (2012). Evaluation in Translation: critical points of translator decision-making. London \& New York: Routledge.

RODRIGUES-JÚNIOR, A. S. (2004). Gender-bend(er)ing male identity: first steps in search of a critical-discursive approach to gay literature translation. Cadernos de tradução, Mariana. 55-79.

RODRIGUES-JÚNIOR, A. S. (2010). Representação gay em corpus literário paralelo. Revista Brasileira de Linguística Aplicada (Impresso), Belo Horizonte, v. 10, n. 3, p. 603-624.

RODRIGUES-JÚNIOR, A. S. (2016). Tradução e Literatura Gay: formas de se fazer pesquisa no campo dos estudos da linguagem. Belo Horizonte: Mercado de Letras.

RODRIGUES-JÚNIOR, A. S.; OLIVEIRA, S. G. (agosto/janeiro 2015). Mudanças ideacionais das representações linguísticas do heterônimo Álvaro de Campos na obra literária de Fernando Pessoae em sua tradução para a língua inglesa. D.E.L.T.A, v. 31, n. 2, p. 391-410.

VINAY, J.-P.; DARBELNET, J. (2000). A Methodology for Translation. In: VENUTI, L. The Translation Studies Reader. London/New York: Routledge. p. 84-93.

WILDE, O. (1962). De Profundis. New York: The Modern Library Classics.

WILDE, O. (2011). De Profundis e outros escritos do cárcare/ tradução de Júlia Tettamanzy Maria Angela Saldanba Vieira de Aguiar. Porto Alegre: L\&PM.

Recebido: 24/02/2017

Aceito: 16/11/2017 